\title{
Midseason droughts review for smallholder farmers in Buffalo Range, Zimbabwe.
}

\author{
Simba Farai Malvern and Chayangira Juwawa \\ Great Zimbabwe University Department of Physics, Geography and Environmental Science.
}

\begin{abstract}
Farmers practising rainfed crop farming are at high risk of poor yields which have been necessitated by uncertain rainfall patterns and high ambient temperatures in recent years. Mid season droughts or dryspells are commonplace during the rainy season (October to March period) in the south eastern region of Zimbabwe and seasonal forecasts issued are not very accurate on seasonal distribution of rainfall. The study seeks to explore a 10 year rainfall season period in terms of dryspell activity using rainfall data, for a district station, provided by the Meteorological Services Department. An analysis of dryspell characteristics that include SNDSP and SMDSL was done using time series plots and regression analysis. A dryspell was defined by ten or more consecutive days of no rainfall during the rainfall season. Data randomness was established using Minitab auto-correlation functions. The analysis established increasing dryspell activity in the first half of the season (October-December period) and data for the station was found to be random. However temperature trends were observed to be decreasing over the ten year period which is a positive because of suppressed evaporation activity. Farmers in the area are advised to delay planting until mid December period, practise stagger planting and water retention techniques. A similar scientific approach can be adopted in other parts of the province and beyond to establish dryspell activities as they pose drought threats to crop farmers.
\end{abstract}

Keywords: midseason, rainfed, resilience, farming, drought, Zimbabwe

\section{Introduction}

Smallholder farmers who have been beneficiaries of the Zimbabwe's land reform programme have had many challenges in recent years as they predominantly practise rain-fed crop farming (Simba $e t$. al, 2013). The south eastern area of Zimbabwe is semi-arid in nature and the southern part of the region falls in agro-ecological regions 4 and 5 respectively where average seasonal rainfall does not exceed $450 \mathrm{~mm}$, however the farmers cannot afford to invest in irrigation equipment (Vincent and Thomas, 1960). The farmers normally grow crops for subsistence purposes with little to sell. The advent of climate change and climate variability have worsened the situation as year in, year out farmers do not realise much yields as there are perennial droughts and sometimes flash floods. The occurrence of mid season droughts is frequent but can be managed to improve the yields. Time series analysis may provide patterns that can be used to guide farmers in their planning for the cropping season. Use of the right seed varieties that can thrive under little moisture and are early maturing, staggering of planting dates and use of water retention techniques can help as a cocktail of ways in which the yield can be improved under the unfavourable conditions.

Assessments of the impacts of climate change on crop production have been done to perfection in the developed countries, but less is known regarding the impacts in developing countries like Zimbabwe (Unganai, 1996). The few studies on environmental change and crop production done in Zimbabwe concentrate mainly on predicting future climatic scenarios for the country and the suitability of these future climates to grow maize which is the staple crop. An example is the UN Framework Convention on Climate Change (1998), which in a study concluded that maize production in Zimbabwe at all sites show a considerable amount of variation under climate change conditions. Maize planted late will not give good yields, thus making maize production a less viable activity under climate change conditions yet it is a staple crop in Zimbabwe. Climate variability and climate change have been apparent with high ambient temperatures recorded with an increase in global temperatures by $0.5{ }^{\circ} \mathrm{C}$ attributed to global warming caused by greenhouse gases. Erratic patterns of rainfall with high frequencies and severities in floods and droughts have also been experienced since 1980 (NASA, 2011).

Maize production at all sites shows a considerable amount of variation under climate change conditions. Maize planted late will not give good yields, thus making maize production a less viable activity under climate change conditions. The simulated changes in crop yields are driven by two factors $\mathrm{CO}_{2}$ enrichment and changes in climate. In the low-lying areas of southern Zimbabwe, for example, it is probable that climate change will turn the region into a non-maize producing area, as exemplified by reduced maize production in Masvingo. If climate change becomes a reality, this area, which represents $42 \%$ of the communal area, will become even more marginal for maize production. Based on site results, seasons could be $25 \%$ shorter than now. Poor rainfall distribution coupled with drought periods, particularly inter-seasonal dry spells have 
Midseason droughts review for smallholder farmers in Buffalo Range, Zimbabwe.

amplified the problem of moisture stress (Paavola, 2003 and Tilyan, 2006) and put at risk between 20 and $30 \%$ of human population living in semi-arid areas (DFID, 2001). A dry spell was first defined and used in British rainfall in 1919 as, a period of at least 15 consecutive days during which none of the days recorded greater than $0.1 \mathrm{~mm}$ of rainfall (Douguedroit, 1987). However it was suggested that the minimum number of consecutive dry days to make up a dry spell has to be identified in a meaningful manner depending on the considered practical problem (Mathugama and Peiris, 2011). Some research work has indicated that depending on the soil depth and retention capacity, dry spells of about a minimum of 10 consecutive dry days cause water stress in many crops thereby reducing yield (Kumar et,al., 2009). Shallow rooted crops in low water retaining soils can experience water stress in less than 7 days. Deep rooted crops in high water retaining soils can go for about 15 days before suffering significant water stress. In addition, it was found that dry spells causes most significant water stress in crops during their first 30 days of their life cycles. The analysis of dry spells is normally done based on two variables namely Maximum Dry Spell Length (MDSL) and number of Dry Spell Periods (NDSP). Already several researchers have done some work towards analysing trends in dry spells using these variables.

Trends in dryspell or midseason activity can point to a concrete pattern that can be managed especially under climate variability circumstances. The study seeks to analyse the activities of midseason droughts for Buffalo Range using climatic data from the region. The data will be analysed using statistical packages as elaborated in the methodology. The findings of this analysis will be packaged in a simple manner that will help a not so literate farmer to follow and adopt.

\section{Objectives}

- To analyse frequency and lengths of midseason droughts in Buffalo range.

- To provide agronomic recommendations on crop farming based on the analysis.

Study area

Masvingo province is located in the south-eastern part of Zimbabwe and it is made up of seven districts as illustrated in Fig. 1.The province lie in agro-ecological regions 3, 4 and 5 where average of $650-800 \mathrm{~mm}$, $450-600 \mathrm{~mm}$ and below $450 \mathrm{~mm}$ respectively of annual rainfall is expected.

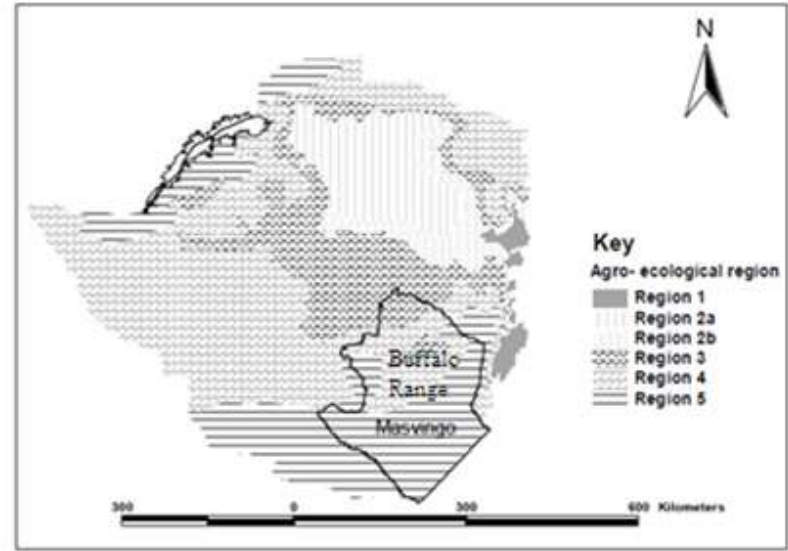

Fig 1: Showing the study area and agro-ecological zones (Vincent and Thomas, 1960).

\section{Data collection}

\section{Methods}

Daily rainfall data that spans for 10 years (period 2003 - 2013) for one station in the province and seasonal total rainfall for the same period were collected from the Meteorological Services Department (MSD). By virtue of the period considered in the study, the findings will provide an indicator to the climate variability for the district in question. The rainy season period for Zimbabwe is 6 months which span from beginning of October to end of March. Dryspells were not considered before the onset of rainfall season. In this study a midseason drought or dry spell is defined as a minimum of 10 consecutive dry days. Dryspell variables to be considered for analysis in this study were the Seasonal Number of Dry Spell Periods (SNDSP), Seasonal Maximum Dry Spell Lengths (SMDSL) and the Seasonal Total Rainfall (STR).

\section{Time series plots}

Graphs plotted are time series graphs of SNDSP, SMDSL and STR for the station. Trend lines with linear equations are used in the plots to illustrate the tendency of the variable with time. A positive gradient points to an increase and a negative to a decrease of the variable with time. 


\section{Model diagnostics}

A model diagnostic was carried out and this primarily was concerned with testing the goodness of fit of a tentative model. The idea is based on two complementary approaches, namely analysis of residuals from fitted models and analysis of over parameterized models. In this study the analysis of residuals from fitted models was used.

\section{Test of randomness (Independence)}

Randomness test was carried out by examining Auto Correlation Functions (ACFs) for the data. Sample ACF of the residual were computed. The method was based on the idea that residuals that were independent or random do not form any pattern and statistically insignificant i.e, they are within $Z_{\alpha / 2}$ standard deviation.

Using runs test, randomness in the residuals can be tested in several ways. Basically, the runs test examines the residuals in sequence to look for patterns. In this case, patterns will occur if the residuals are correlated.

\section{Results And Discussions}

Results are given in two forms which are time series plots and in tests for randomness.

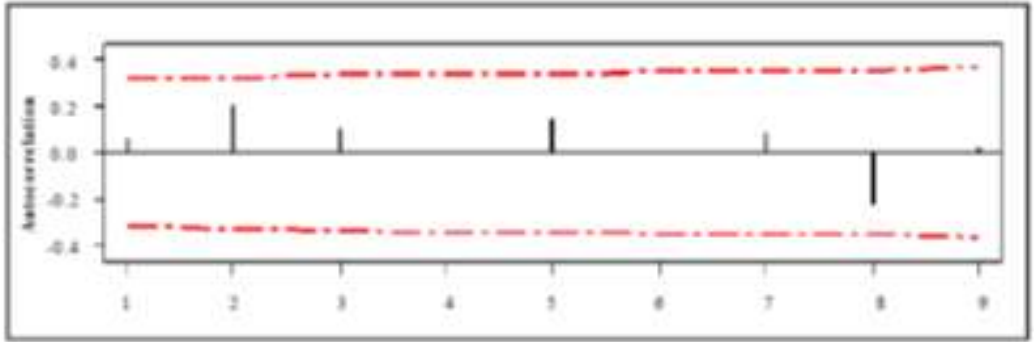

Fig 2: Autocorrelation function for SMDSL for Buffalo range station

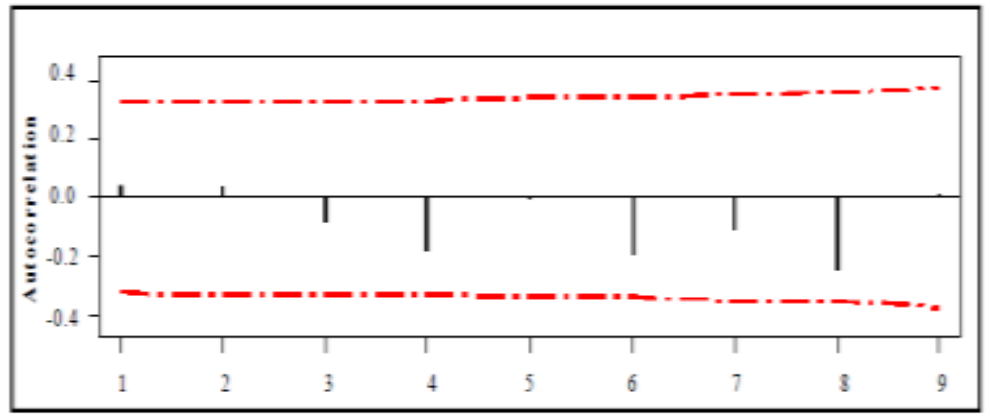

Fig 3: Autocorrelation function for SNDSP for Buffalo range station

Randomness test was done for the Buffalo Range station data on two parameters which are SNDSP and SMDSL as shown in Fig. 1 and Fig. 2. It shows a test of randomness on the data used to plot the dryspell variables SNDSP and SMDSL using Minitab Auto-Correlation function. The two graphs show that all the lags are not cutting the red line which implies that the data used for both stations is random. This implies the data is not following any particular trend and cannot be modelled in statistical models to make future forecasts.

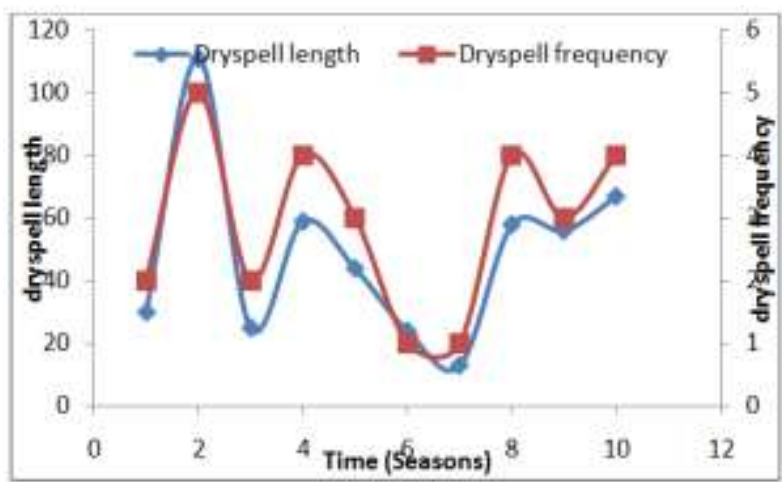

Fig 4: Time series for dryspell length and frequency 
Midseason droughts review for smallholder farmers in Buffalo Range, Zimbabwe.

The two variables show a strong relationship, indicating that one can be used to forecast or predict another.

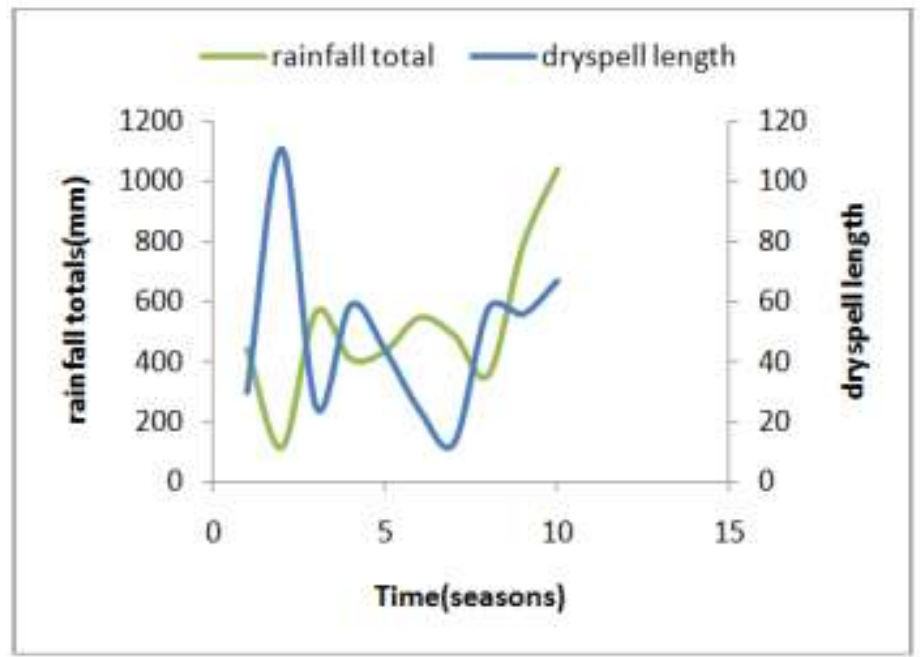

Fig 5: Time series for seasonal rainfall total and dryspell length.

Little to no relationship is observed on the two variables as crests of one graph coincide with troughs of the other. The two are almost out of phase.

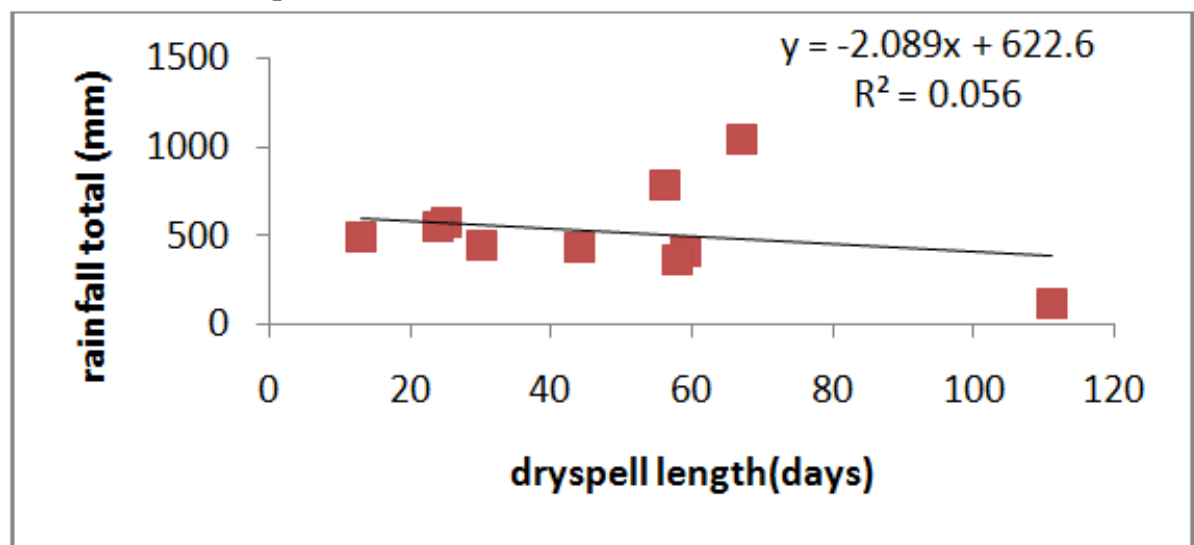

Fig 6: Correlation between rainfall seasonal total and dryspell length.

There seem to be no correlation between the seasonal rainfall total and the dryspell length as indicated by a small value for the coefficient of regression.

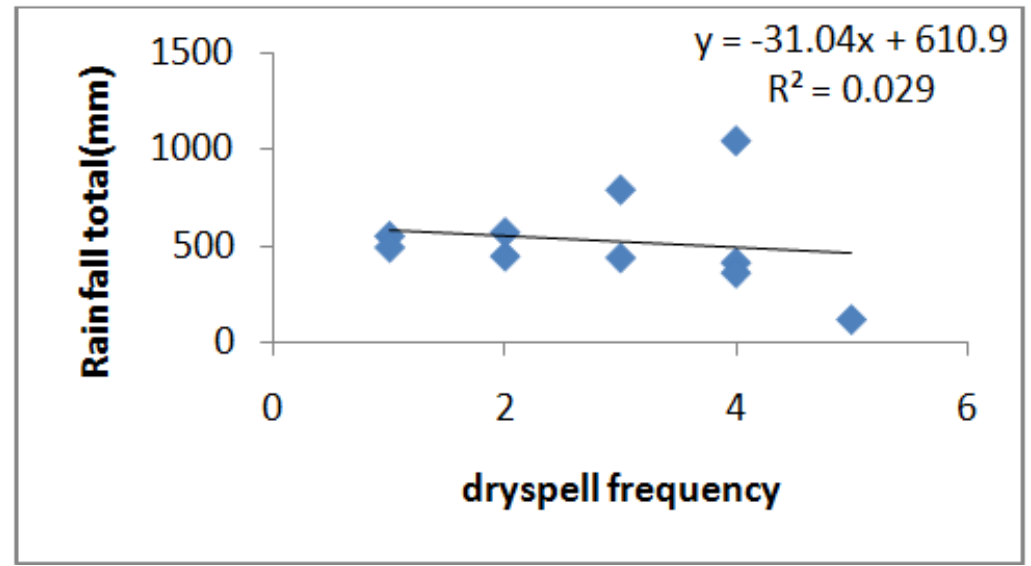

Fig 7: Correlation between rainfall and dryspell frequencies

There seem to be no correlation between the total seasonal rainfall received and the dryspell experienced. The correlation coefficient indicates a small value which points to a weak relationship between the two variables. 


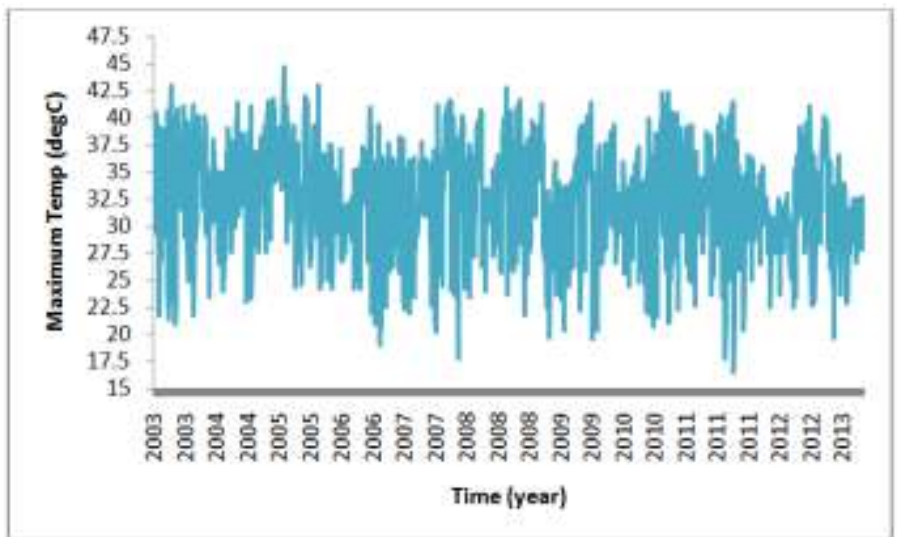

Fig 8: Time series variation of maximum temperatures for the Buffalo range station

The seasonal maximum temperatures show huge spikes, with highest temperatures recorded in 2005 and minimum in 2011.The trend of maximum temperatures seem to be decreasing over the 10 year period. Despite the mid season drought activity being high, the evaporating temperatures are decreasing, which may be a positive to crop farming as moisture can be retained for longer periods.

Table 1: showing dryspell activities for the Buffalo range station

\begin{tabular}{|l|l|l|l|l|}
\hline Year & Season period & $\begin{array}{l}\text { Dryspell cumulative } \\
\text { total length }\end{array}$ & $\begin{array}{l}\text { Dryspell } \\
\text { frequency }\end{array}$ & $\begin{array}{l}\text { Dryspell } \\
\text { activity length }\end{array}$ \\
\hline 2003 & Oct-Dec & 0 & 0 & 0 \\
\hline 2004 & Jan-Mar & 30 & 2 & 15 \\
\hline 2004 & Oct-Dec & 66 & 4 & $12,13,27$ \\
\hline 2005 & Jan-Mar & 45 & 1 & 45 \\
\hline 2005 & Oct-Dec & 14 & 1 & 14 \\
\hline 2006 & Jan-Mar & 11 & 1 & 11 \\
\hline 2006 & Oct-Dec & 30 & 2 & 14,16 \\
\hline 2007 & Jan-Mar & 29 & 2 & 10,19 \\
\hline 2007 & Oct-Dec & 34 & 2 & 11,23 \\
\hline 2008 & Jan-Mar & 10 & 1 & 10 \\
\hline 2008 & Oct-Dec & 24 & 1 & 24 \\
\hline 2009 & Jan-Mar & 0 & 0 & 0 \\
\hline 2009 & Oct-Dec & 13 & 1 & 13 \\
\hline 2010 & Jan-Mar & 0 & 0 & 0 \\
\hline 2010 & Oct-Dec & 30 & 2 & 18,12 \\
\hline 2011 & Jan-Mar & 28 & 2 & 15,13 \\
\hline 2011 & Oct-Dec & 56 & 3 & $15,25,16$ \\
\hline 2012 & Jan-Mar & 0 & 0 & 0 \\
\hline 2012 & Oct-Dec & 57 & 3 & $16,25,16$ \\
\hline 2013 & Jan-Mar & 10 & 1 & 10 \\
\hline & & & & \\
\hline
\end{tabular}

The table shows the variations of dryspell activities with seasons. The highest frequencies in dryspells are recorded within the October -December seasonal period, whereas the least ones are in January -March period. Crop farming is ideal therefore around mid December to end of December to reduce the losses due to midseason droughts.

\section{Conclusion}

The data used in this study is for a 10 year period and largely give a climatic variability picture for the Buffalo range area and its surroundings. Observations that were drawn from the analysis were that most midseason droughts occurred in the first half of the season period which is the October to December period. Farmers in this area need to delay their planting time as productive rains come around mid December period. They should practice water retention methods like mulching, intercropping and other to help retain the soil moisture. Stagger planting also helps to minimise losses as risk is spread by the practice. The upside of the analysis though was that during the 10 year period the temperatures were dropping. The temperature trend is unexpected globally since there is documented global warming which implies a rise in temperature. There are factors however that may contribute to the drop in temperature like topographical features, vegetation densities, water bodies in the vicinity among others. A similar review of other areas with more weather stations involved and data of longer periods will help give much more accurate findings.

\section{References}


[1]. DFID (2001) Strategy for research on renewable natural resources, Technical Report for the DFID's Nat. Resour. Systems Programme: Semi Arid Systems.

[2]. Douguedroit A.(1987), The variations of dry spells in Marseilles from 1865 to 1984, Int. J. Climat. 7(6), 541-551.

[3]. Empirical results and analysis, www.essaycoursework.com, (2012).

[4]. Kumar N., Shamim T., Lall P., Sagar S. and Kumar A. (2009). Assessment of flood with it social concequences and environmental law, J.Environ. Res. Develop., 3(4), 1013-1019.

[5]. Mathugama S.G. and Peiris T.S.G. (2011). Critical evaluation of dry spell research, Int.J.Basic appl. Sci. 11(6), 01-08.

[6]. NASA (2011) http://data.giss.nasa.gov/gistemp.

[7]. Paavola J. (2003) Vulnerability to climate change in Tanzania, sources, substance and solutions, A paper presented at the inaugural workshop of Southern Africa Vulnerability Initiative (SAVI) in Maputo, Mozambique June 19-21.

[8]. presented at the Int. Workshop on Climate and Land Degradation, Lamgando Conference Hall, Arusha, Tanzania UNFCCC, 11-15. http://unfccc.int.

[9]. Simba F et.al (2013). Prediction of yield and bimass productions: A remedy to climate change in semi-arid regions of Zimbabwe. Int. J of Adv Agricultural Research. Vol 1, pp. 14-21

[10]. Tilya F. F. and Mhita M. S.(2006) Frequency of wet and dry spells in Tanzania, A paper

[11]. Vincent V. and Thomas R.G (1960). An agricultural survey of Southern Rhodesia:Part I : Agro-ecological surveyvulnerability and adaptation assessmentsin Zimbabwe, Government Printers, Harare.

[12]. Zimbabwe's Initial National Communication under the United Nations Framework Convention on Climate Change (1998). A report on expected impacts of climate change 